\title{
Uptake of Outpatient Monoclonal Antibody Treatments for COVID-19 in the United States: a Cross-Sectional Analysis
}

J Gen Intern Med 36(12):3922-4

DOI: $10.1007 / \mathrm{s} 11606-021-07109-5$

(C) Society of General Internal Medicine 2021

\section{INTRODUCTION}

The Food and Drug Administration (FDA) has issued emergency use authorizations for three monoclonal antibodies for the outpatient treatment of symptomatic coronavirus disease 2019 (COVID-19) ${ }^{1}$ in patients at high risk for progressing to severe disease, and the federal government has purchased and allocated nearly 1 million antibody treatments. ${ }^{2}$ Monoclonal antibodies remain the only approved outpatient therapies available for COVID-19 and media reports have speculated they may be underutilized ${ }^{3}$ however, data on utilization has not been published.

\section{METHODS}

We examined outpatient medical claims from Symphony Health, a national medical claims database covering over 200 million US patients, made available through the COVID-19 Research Database consortium. ${ }^{4}$ Receipt of monoclonal antibody treatments (bamlanivimab, casirivimab/ imdevimab, and bamlanivimab/etesevimab) between November 9, 2020, and April 11, 2021, was determined by antibodyspecific Current Procedural Terminology codes according to Centers of Medicare and Medicaid Services guidance. ${ }^{5}$ Descriptive characteristics of treatment recipients and the underlying study base were compared using 2-sided chi-2 tests, with an alpha set at $P<.05$. Weekly trends in the use of each treatment were plotted. All analyses were conducted using Stata 16.1. The study was classified as exempt by the Beth Israel Deaconess Medical Center Institutional Review Board.

\section{RESULTS}

The study base included 211 million patients of whom 69,377 receive monoclonal antibody treatments during the study period (Table 1). Bamlanivimab accounted for $84.6 \%$ of administered treatments, casirivimab/imdevimab for $12.8 \%$ and

Received June 28, 2021

Accepted August 19, 2021

Published online September 8, 2021 bamlanivimab/etesevimab for $2.6 \%$. The majority of patients receiving antibody treatments were younger than 65 years $(57.5 \%)$, female $(53.8 \%)$, had commercial insurance $(62.3 \%)$, and were located in the South $(50.8 \%)$. Though patients with Medicaid compromised $10.0 \%$ of the study base, they compromised only $3.3 \%$ of patients receiving monoclonal antibodies. Weekly use of monoclonal antibodies increased throughout 2020, peaking the week of January 4,

Table 1 Characteristics of Patients Receiving Monoclonal Antibodies for COVID-19 and the Study Base Population

\begin{tabular}{|c|c|c|c|c|}
\hline \multirow[b]{2}{*}{ Characteristic } & \multicolumn{2}{|c|}{$\begin{array}{l}\text { Patients receiving } \\
\text { monoclonal } \\
\text { antibodies }\end{array}$} & \multicolumn{2}{|c|}{$\begin{array}{l}\text { Patients in symphony } \\
\text { health database }\end{array}$} \\
\hline & No. & $\%$ & No. & $\%$ \\
\hline $\begin{array}{l}\text { Total } \\
\text { Gender }\end{array}$ & 69,377 & $100.0 \%$ & $211,239,305$ & $100.0 \%$ \\
\hline Female & 37,344 & $53.8 \%$ & $117,181,902$ & $55.5 \%$ \\
\hline Male & 32,031 & $46.2 \%$ & $94,033,559$ & $44.5 \%$ \\
\hline Unknown & $*$ & $*$ & 23,844 & $<0.1 \%$ \\
\hline \multicolumn{5}{|l|}{ Age } \\
\hline$<18$ & 391 & $0.6 \%$ & $39,507,671$ & $18.7 \%$ \\
\hline $18-34$ & 3,672 & $5.3 \%$ & $42,038,531$ & $19.9 \%$ \\
\hline $35-44$ & 5,695 & $8.2 \%$ & $24,617,771$ & $11.7 \%$ \\
\hline $45-54$ & 10,431 & $15.0 \%$ & $26,400,781$ & $12.5 \%$ \\
\hline $55-64$ & 19,681 & $28.4 \%$ & $30,641,321$ & $14.5 \%$ \\
\hline$>65$ & 29,504 & $42.5 \%$ & $44,635,884$ & $21.1 \%$ \\
\hline Unknown & * & * & $3,397,346$ & $1.6 \%$ \\
\hline \multicolumn{5}{|l|}{ Primary payer } \\
\hline Commercial & 43,191 & $62.3 \%$ & $159,647,410$ & $75.6 \%$ \\
\hline Medicare & 22,741 & $32.8 \%$ & $22,890,227$ & $10.8 \%$ \\
\hline Medicaid & 2,303 & $3.3 \%$ & $21,099,366$ & $10.0 \%$ \\
\hline Government & 762 & $1.1 \%$ & $3,357,504$ & $1.6 \%$ \\
\hline Cash & 66 & $0.1 \%$ & 341,132 & $0.2 \%$ \\
\hline Unknown & 314 & $0.5 \%$ & $3,903,666$ & $1.8 \%$ \\
\hline \multicolumn{5}{|l|}{ Race/ethnicity } \\
\hline Caucasian & 37,992 & $54.8 \%$ & $64,586,764$ & $30.6 \%$ \\
\hline African American & 5,595 & $8.1 \%$ & $11,645,740$ & $5.5 \%$ \\
\hline Hispanic & 4,835 & $7.0 \%$ & $8,841,446$ & $4.2 \%$ \\
\hline Asian & 564 & $0.8 \%$ & $1,694,072$ & $0.8 \%$ \\
\hline Other & 823 & $1.2 \%$ & $1,475,227$ & $0.7 \%$ \\
\hline Unknown & 19,568 & $28.2 \%$ & $122,996,056$ & $58.2 \%$ \\
\hline \multicolumn{5}{|l|}{ Household income } \\
\hline$<=\$ 29,999$ & 9,080 & $13.1 \%$ & $18,728,477$ & $8.9 \%$ \\
\hline$\$ 30-49,999$ & 7,360 & $10.6 \%$ & $14,029,011$ & $6.6 \%$ \\
\hline$\$ 50-74,999$ & 9,687 & $14.0 \%$ & $15,799,682$ & $7.5 \%$ \\
\hline$\$ 75-99,999$ & 8,744 & $12.6 \%$ & $13,965,483$ & $6.6 \%$ \\
\hline$\$ 100,000+$ & 13,679 & $19.7 \%$ & $23,616,317$ & $11.2 \%$ \\
\hline Unknown & 20,827 & $30.0 \%$ & $125,100,335$ & $59.2 \%$ \\
\hline \multicolumn{5}{|l|}{ Region } \\
\hline Northeast & 10,114 & $14.6 \%$ & $42,357,553$ & $20.1 \%$ \\
\hline South & 35,091 & $50.6 \%$ & $77,759,778$ & $36.8 \%$ \\
\hline Midwest & 17,567 & $25.3 \%$ & $43,853,111$ & $20.8 \%$ \\
\hline West & 5,287 & $7.6 \%$ & $36,432,944$ & $17.2 \%$ \\
\hline Unknown & 1,318 & $1.9 \%$ & $10,835,919$ & $5.1 \%$ \\
\hline
\end{tabular}

Note: Cells with fewer than 10 observations redacted for data privacy and marked with *. P values for chi-2 comparison of characteristics between patients receiving monoclonal antibodies and Symphony Health population all $<.001$ 


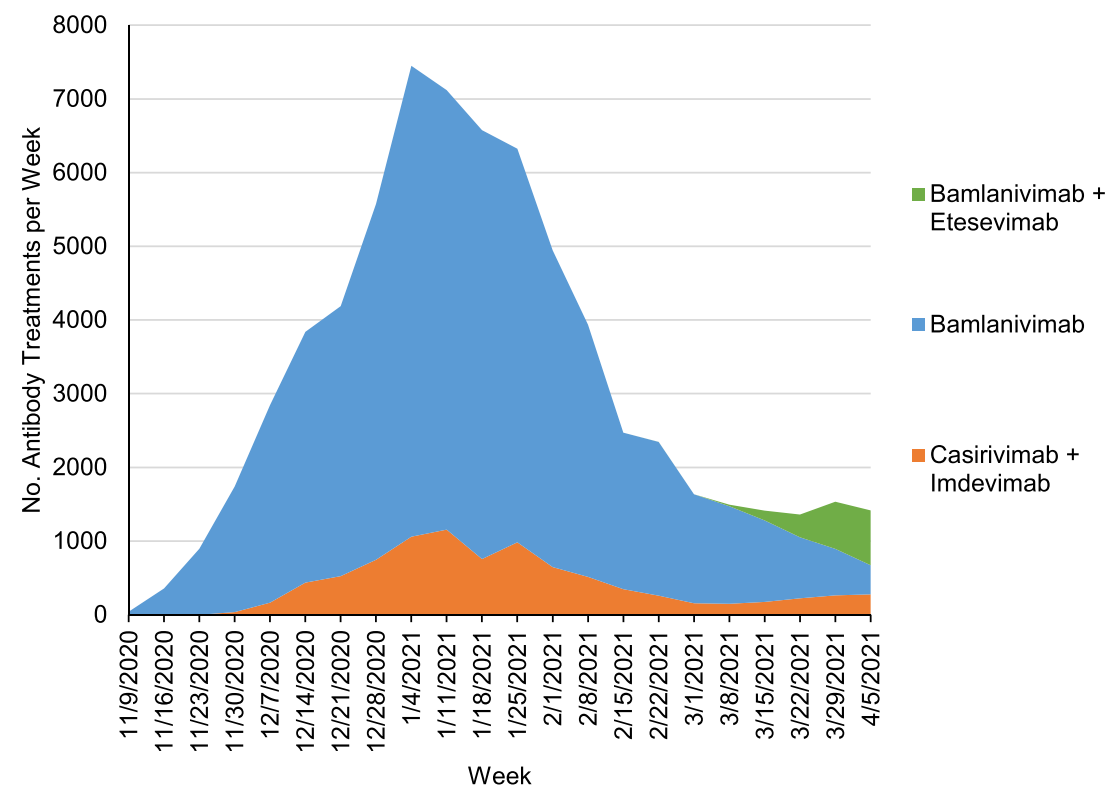

Figure 1 Weekly trends in the administration of monoclonal antibodies for COVID-19. Notes: Analysis of Symphony Health claims from November 9, 2020, and April 11, 2021. Dates on the $x$-axis refer to the first day of a 7-day week. The dates of emergency use authorizations were November 9, 2020, for bamlanivimab, November 21, 2020, for casirivimab/imdevimab, and February 9, 2021, for bamlanivimab/ etesevimab. The emergency use authorization for bamlanivimab administered alone was revoked on April 14th, 2021.

2021, with 7,243 treatments given, and thereafter declined through the end of the study period (Fig. 1).

\section{DISCUSSION}

In this medical claims study including $62 \%$ of the US population, we observe fewer than 70,000 patients received monoclonal antibody treatments for COVID-19 between first FDA emergency use authorization and April 11, 2021. During this time period, over 20 million cases of COVID-19 were diagnosed, 2.5 million monoclonal antibody treatments were purchased by the US government, and nearly 1 million treatments were allocated to states. ${ }^{2}$

Our findings of low uptake of monoclonal antibody treatments contrast to prior reports of increased use of unauthorized therapies. ${ }^{6}$ Reasons for low uptake warrant future research and could reflect stockpiling of allocated treatments, limited distribution by health systems, barriers to patient access to treatments which require intravenous infusion, or hesitancy to adopt treatments by providers and patients. The initial authorization of monoclonal antibodies occurred on the cusp of the largest surge in COVID-19 infections and the initial COVID-19 vaccine rollout. If health systems lacked the capacity to immediately develop additional infrastructure for administering antibody treatments due to competing priorities, we would have expected to see gradual growth in the use of monoclonal antibodies; however, we find that antibody use declined throughout 2021.

Despite limitations of missing data, the observed demographic and insurer differences in the treated population compared to the study base highlight a possible disparity in access. As many patients receive a COVID-19 diagnosis outside of the health system, through government, school, workplace, and other testing sites, our study was unable to determine the symptomatic population who would have been potentially eligible for monoclonal antibody treatments. Furthermore, these testing sites may not be equipped to refer patients to receive monoclonal antibody treatments, particularly if they do not already have a usual source of healthcare.

The public interest would be well-served by improved transparency on the allocation and administration of monoclonal antibody treatments, including data necessary to assess equitable access to treatments.

\section{Acknowledgements:}

The data, technology, and services used in the generation of these research findings were provided by the COVID-19 Research Database partners, who are acknowledged at https:// covid19researchdatabase.org/.

Role of Funder Statement: Google.org had no role in the design and conduct of the study; collection, management, analysis, and interpretation of the data; preparation, review, or approval, of the manuscript; and decision to submit the manuscript for publication.

Timothy S. Anderson, MD, MAS $S^{1,2,3}$

Ashley L. O'Donoghue, $\mathrm{PhD}^{2}$

Tenzin Dechen, $M_{P H}{ }^{2}$

Oren Mechanic, MD, MPH ${ }^{4}$

Jennifer P. Stevens, $M D, M S^{2,3,5}$

${ }^{1}$ Division of General Medicine, Beth Israel Deaconess Medical Center,

Boston, MA, USA 
${ }^{2}$ Center for Healthcare Delivery Science, Beth Israel Deaconess Medical Center,

Boston, MA, USA

${ }^{3}$ Harvard Medical School,

Boston, MA, USA

${ }^{4}$ Harvard Medical Faculty Physicians at Beth Israel Deaconess Medical Center,

Boston, MA, USA

${ }^{5}$ Division of Pulmonary, Critical Care and Sleep Medicine, Beth Israel Deaconess Medical Center, Boston, MA, USA

Corresponding Author: Timothy S. Anderson, MD, MAS; Division of General Medicine, Beth Israel Deaconess Medical Center, Boston, MA, USA (e-mail: tsander1@bidmc.harvard.edu).

Author Contribution Dr. Anderson had full access to all the data in the study and take responsibility for the integrity of the data and the accuracy of the data analysis as the guarantor. Dr. Anderson attests that all listed authors meet authorship criteria and that no others meeting the criteria have been omitted.

Study concept and design: Anderson, Stevens

Acquisition, analysis, or interpretation of data: All authors

Drafting of the manuscript: Anderson

Critical revision of the manuscript for important intellectual content: All authors

Statistical analysis: Anderson, Dechin, O'Donoghue

Obtained funding: Stevens

Administrative, technical, or material support: Stevens

Study supervision: Stevens

Funding Drs. O'Donoghue and Stevens and Ms. Dechen are funded by an unrestricted philanthropic gift from Google.org.

\section{Declarations:}

Conflict Interest: Dr. Anderson reports grant funding from the National Institute on Aging and American College of Cardiology outside of the submitted work.

Disclaimer

The content is solely the responsibility of the authors and does not necessarily represent the official views of Beth Israel Deaconess Medical Center or Harvard Medical School.

\section{REFERENCES}

1. U.S. Food and Drug Administration. Emergency Use Authorization. Accessed June 2, 2021. Available from: https://www.fda.gov/emergencypreparedness-and-response/mcm-legal-regulatory-and-policy-framework/emergency-use-authorization\#coviddrugs

2. U.S. Department of Health \& Human Services. BARDA's Expanding COVID-19 Medical Countermeasure Portfolio. Accessed June 2, 2021. Available from: https://www.medicalcountermeasures.gov/app/barda/ coronavirus/COVID19. aspx?filter=therapeutic

3. Thomas K, Robbins R. Covid Antibody Drugs Go Unused as Need Soars. New York Times. Published Dec. 23, 2020 Updated Feb. 26, 2021.

4. COVID-19 Research Database. Accessed May 27, 2021. https:// covid19researchdatabase.org

5. Centers for Medicare and Medicaid Services. COVID-19 Vaccines and Monoclonal Antibodies. Accessed June 2, 2021. Available from: https:// www.cms.gov/medicare/medicare-part-b-drug-average-sales-price/ covid-19-vaccines-and-monoclonal-antibodies

6. Geller AI, Lovegrove MC, Lind JN, Datta SD, Budnitz DS. Assessment of Outpatient Dispensing of Products Proposed for Treatment or Prevention of COVID-19 by US Retail Pharmacies During the Pandemic. JAMA Intern Med. Published online February 11, 2021. doi:https://doi.org/10.1001/ jamainternmed.2021.0299

Publisher's Note: Springer Nature remains neutral with regard to jurisdictional claims in published maps and institutional affiliations. 